University of Rhode Island

DigitalCommons@URI

Open Access Dissertations

1991

\title{
Level of Satisfaction and Commitment to a Decisional Choice as Mediated by Locus of Control
}

Michael Anthony Surrette

University of Rhode Island

Follow this and additional works at: https://digitalcommons.uri.edu/oa_diss

\section{Recommended Citation}

Surrette, Michael Anthony, "Level of Satisfaction and Commitment to a Decisional Choice as Mediated by Locus of Control" (1991). Open Access Dissertations. Paper 966.

https://digitalcommons.uri.edu/oa_diss/966

This Dissertation is brought to you for free and open access by DigitalCommons@URI. It has been accepted for inclusion in Open Access Dissertations by an authorized administrator of DigitalCommons@URI. For more information, please contact digitalcommons-group@uri.edu. 
LEVEL OF SATISFACTION AND COMMITMENT TO A DECISIONAL CHOICE AS MEDIATED BY LOCUS OF CONTROL

BY

MICHAEI, ANTHONY SURRETTE

A DISSERTATION SUBMITTED IN PARTIAL FULFILLMENT OF THE REQUIREMENTS FOR THE DEGREE OF DOCTOR OF PHILOSOPHY

IN

PSYCHOLOGY

\#2=239.9.

UNIVERSITY OF RHODE ISLAND

1991 
Abstract

The present study investigated the relationship between an increase in decisional choices and an individual's subsequent level of satisfaction and commitment with their choice. An individual's locus of control was also investigated as a mediating variable between decisional choice and satisfaction. Participants read a brief biographical scenario which described an individual's attempt to get accepted into graduate school. The scenario portrayed the individual getting accepted into either one, three, or five graduate programs from a list of ten. Participants were required to complete two measures of satisfaction (Job in General Scale \& Kunin's Faces Scale) and one measure of commitment (Organizational Commitment Questionnaire) to indicate their perceptions of the scenario outcome. Rotter's Locus of Control scale was also administered. It was hypothesized that there would be an interaction between locus of control and degree of decisional choice. It was also hypothesized that there would be a positive relationship between degree of choice and level of commitment. Lastly, it was hypothesized that there would be a positive relationship between level of satisfaction and level of commitment to a decisional choice. Results 
of the present study failed to support hypothesis one. Internals were more satisfied with an increase in choice as predicted. But, externals were also more satisfied with an increase in decisional choice. Results provide support for hypotheses two. Individuals reported that they would be more committed to a decisional choice if it was selected from a greater number of alternatives. Results also provided support for hypothesis three. It was found that there was a significant relationship between an individual's level of satisfaction and commitment with choice. Exploratory post hoc analysis revealed a small, but significant effect for locus of control. These latter results suggest a small effect where internals and externals react differently to an increase in choice with regard to their level of satisfaction and commitment. Suggested areas for future research to further investigate these results are encouraged and outlined. 
Acknowledgement

I wish to extend my sincere "thanks" to the members of my dissertation committee, Dr. Lisa L. Harlow, Dr. William T. Vosburgh, and Dr. Elizabeth A. Cooper, for their guidance and continual support over this past year and especially during this project. It was refreshing to work with a group of individuals who believed in saying exactly what was on their mind and who trusted that I was secure enough with myself to take their feedback in the spirit it was intended.

I would like to express my gratitude toward Dr. Harlow for her support over the past three years; both academically and personally. I want to thank her for allowing me the freedom to reach for my goals while still maintaining a watchful eye to make sure I did not reach too far beyond my limits.

Finally, I wish to thank Dr. Albert J. Lott for his exhaustive efforts which made my presence at URI possible and Dr. Charles E. Collyer for his continued support and reassurance in my ability over the years. 
Table of Contents

Page

List of Tables ...................... vii

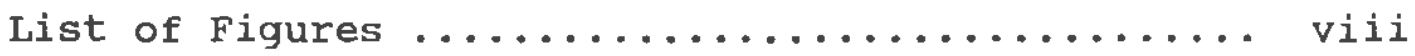

List of Appendices $\ldots \ldots \ldots \ldots \ldots \ldots \ldots \ldots \ldots$ ix

Statement of Problem $\ldots \ldots \ldots \ldots \ldots \ldots \ldots \ldots \ldots \ldots, 1$

Justification of the study $\ldots \ldots \ldots \ldots \ldots \ldots \ldots \ldots, 2$

Degree of Choice \& Level of Satisfaction .... 3

LOC, Satisfaction, \& Level of Choice ...... 12

Commitment, Degree of Choice, \& LOC ........ 14

Research Hypotheses ............... 17

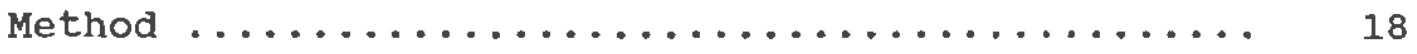

Participants $\ldots \ldots \ldots \ldots \ldots \ldots \ldots \ldots \ldots \ldots \ldots$

Instruments $\ldots \ldots \ldots \ldots \ldots \ldots \ldots \ldots \ldots \ldots$

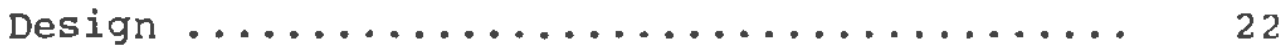

Procedure $\ldots \ldots \ldots \ldots \ldots \ldots \ldots \ldots \ldots \ldots \ldots, 22$

Results .......................... 24

Manipulation check $\ldots \ldots \ldots \ldots \ldots \ldots \ldots \ldots .28$

Intercorrelation Among DV ............ 29

Exploratory Data Analysis $\ldots \ldots \ldots \ldots \ldots \ldots .30$ 


\section{Table of contents}

(continued)

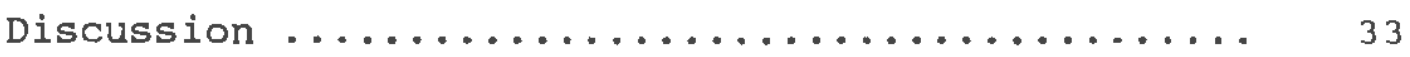

Hypothesis one ..................... 33

Hypothesis Two ...................... 35

Hypothesis Three ..................... 36

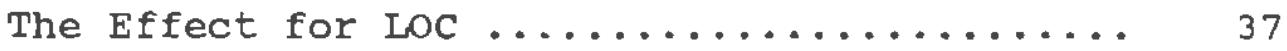

Exploratory Analysis .................. 40

Appropriateness of Sample .............. 42

Additional Factors Effecting Satisfaction ... 43

and commitment

Future Research Needs ................ 45

Implications and Applications .......... 45

References ............................ . . 49

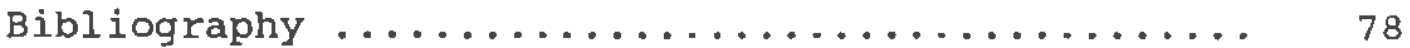




$$
\text { List of Tables }
$$

Table

Page

1. Means and Standard Deviations for Reported 68 Satisfaction with Chosen Graduate Program as Measured with the Job in General scale

2. Means and Standard Deviations for Reported 69 Satisfaction with Chosen Graduate Program as Measured by Kunin's Faces Scale

3. Means and Standard Deviations for Reported Degree of Commitment with Chosen Graduate School as Measured by the organizational Commitment Questionnaire

4. Mean Locus of Control Scores for Internals and Externals Across the Three Dependent Variables

5. Frequency Distribution of Scores on Rotter's 72 Locus of Control Scale 


\section{List of Figures}

Figure

Page

1. Mean Level of Satisfaction Across the

Three Levels of Choice as Measured by the

Job in General Scale

2. Mean Level of Satisfaction Across the

Three Levels of Choice as Measured by

Kunin's Faces scale

3. Mean Level of Commitment Across the Three

Levels of Choice as Measured by the

organizational Commitment Questionnaire

4. Comparison of the Effect of LOC on

Satisfaction with Choice for Two Methods of Categorizing LOC Scores: A Mean Split Shown on the Left; An Upper and Lower Third Split Shown on the Right

5. Comparison of the Effect of LOC on

Commitment with choice for Two Methods of Categorizing LOC Scores: A Mean Split Shown on the Left; An Upper and Lower Third Split Shown on the Right 


\section{List of Appendices}

Appendix

Page

A Biographical Scenario: Version one ....... 54

B Biographical Scenario: Version Two ....... 55

C Biographical Scenario: Version Three ..... 56

D Kunin's Faces scale ............... 57

E Job in General scale ............... 58

F Organizational Commitment Questionnaire ... 61

G Rotter's Locus of Control scale .........63 
TITLE: Level of Satisfaction and commitment to a Decisional Choice as Mediated by Locus of control.

STATEMENT OF THE PROBLEM

The present study investigated the relationship between a person's decisional choice, and their locus of control as they relate to their level of satisfaction and degree of commitment to the choice. It is hypothesized that there will be an interaction effect between degree of choice and a person's locus of control on their level of satisfaction. It is predicted that a person with an internal locus of control will be more satisfied with an increase in choice. Those with an external locus of control are expected to be less satisfied with an increase in choice. It is hypothesized that there will be a significant effect for level of choice on a person's degree of commitment. It is predicted that a person who chooses from a greater number of alternatives will be more committed to their decision. A positive relationship between a person's level of satisfaction and level of commitment to their decisional choice is also hypothesized.

A person's level of satisfaction has been shown to be related to the degree of choice the person is allowed in selecting the activity in which they are engaged. 
Research has also provided support for a relationship between a person's level of commitment with a decision based on the degree of choices available. It appears that the more choices a person selects from, the greater their commitment to and satisfaction with the task or goal. Past research has examined the relationship between a person's satisfaction and the degree of choice in both an absolute fashion (choice / no choice) and in a relative degree of choice design (low choice / high choice). The research investigating this relationship has produced mixed results as to the influence that degree of choice has on a person's level of satisfaction. A variable which has been shown to account for some of the mixed results is a person's attributional process or their locus of control. Research has suggested that locus of control may act as a mediating variable in the relationship between degree of choice and level of satisfaction with decision. JUSTIFICATION FOR AND SIGNIFICANCE OF THE STUDY

A phenomena which has the attention of many individuals, professional as well as lay-people, is the search for a highly satisfying life. Factors which may influence the overall satisfaction of a person's life range from being physically and mentally fit to acquiring many material possessions. In the span of a person's life, events will occur which bring them a great deal of satisfaction as well as events which contribute to their 
lowest level of satisfaction. According to Rotter's theoretical formulation of social learning (Rotter, 1954), these factors are either sought after or avoided depending on their reinforcing quality and the expectancies of future outcome. The present study will examine two factors, degree of choice and locus of control, which are expected to have an effect on a person's level of satisfaction and commitment to their decisional choice. Degree of Choice and Level of Satisfaction

When a person is asked what contributes to their satisfaction with a given decision the answers will generally vary. A factor which has been shown to be related to a person's level of satisfaction with their decision has been their freedom of choice over the decision (Mannell, Zuzanek, \& Larson, 1988). Mannell et al. denonstrated this relationship in the lives of older adults. The researchers used the Experience Sampling Method (ESM: Larson \& Csikszentmihalyi, 1983) to collect their data. During a one week period 92 retired adults (40 men and 52 women) carried an electric pager and an experience sampling form (ESF). On the ESF, each participant responded to a series of questions regarding the situation they were in. One of the questions on the ESF was "How much choice did you have in selecting this 
activity?" on a 10 point scale ranging from none (0) to very much (9). One of the dependent variables was a measure of mood state. Mood state (affect) was assessed using two 7 point semantic differential items (happy-sad, cheerful-irritable). Participants who indicated that they chose the activity they were engaged in reported having a higher level of positive affect.

Research which has assessed the effect having a choice of behaviors has on an individual's satisfaction has been conducted in a wide variety of contexts (e.g., organizations, family \& single life, academia, etc.). A person who is given a choice over their behavior appears to have a higher level of satisfaction with their chosen activity in many different situations. Findings from a number of research studies, presented below, highlight the range of situations where having a decisional choice affects a person's level of satisfaction. Kimmel, Price, and Walker (1978) investigated the effect of having a choice over when to retire on an individual's attitude and satisfaction with retirement. Individuals who reported that they retired voluntarily from major corporations were compared to nonvoluntary retirees. The researchers mailed a total of 2,563 questionnaires to a predominately male sample; 1,486 usable responses were examined. The questionnaire included items addressing the individual's decision to 
retire, extent of preparation for retirement, attitude about retirement, and the Retirement Description Index (RDI) . Results revealed that voluntarily retired individuals were significantly higher on all measures of retirement satisfaction in the RDI compared to the nonvoluntary retirees. The voluntary group also reported having an easier time adjusting to retirement.

The effects of having a choice of behavioral alternatives on a person's level of satisfaction has also been demonstrated in the medical community. Morris and Ingham (1988) used two groups of breast cancer patients, both of which required surgery. The patients were matched for stage of disease and age. The groups differed in their ability to select the type of surgery to receive; group one was offered a choice of surgeries, group two was not offered a choice of surgeries. The data collected from the cancer patients and their husbands were: attitude toward the future, ability to undertake work, belief about coping, and physical functioning. Data were recorded pre-operatively, 2 months, and 10 months postoperative. The results indicate that the patients who were offered a choice of surgeries were more satisfied with the complete process (pre and post-operatively) than patients, and their husbands, who had no choice but were forced to take a specified type of surgery. 
Another area where having a choice has been shown to influence a person's level of satisfaction is in the area of marital status. Austrom and Hanel (1985) conducted a survey of unmarried Canadian adults. A self-selected sample of 482 unmarried adults responded to questions about their reasons, motivations, and satisfaction with single life. Results from the survey revealed a mean level of satisfaction of 6.8 on an 11-point scale. The sample was further divided into two groups: individuals who said they were single by choice, and individuals who said they were single due to circumstances beyond their control. An analysis of variance revealed a significant mean difference in satisfaction between those who were single by choice (mean $=8.2$ ) and those who were single for reasons beyond their control (mean $=5.0$ ) .

Research has also demonstrated that having a choice in and of itself may increase an individual's satisfaction, regardless of whether the available choices are used (Gorrell \& Cramond, 1988). Gorrell and cramond's research concerned the use of written justifications to back up a student's response on a multiple choice exam. A student, who desired, could write a justification for their selected response on the multiple choice exam. The researchers used a self-constructed scale to assess the student's attitude toward the use of written justifications in the multiple choice exam format. 
Results from the attitude scale revealed a uniformly positive attitude toward the use of written justifications. Intuitively these results are not surprising. An interesting point is that even those students who did not use the option of writing a justification for their answers had a high positive (more satisfied) attitude toward the testing format.

The above research provides support for the belief that individuals prefer to have a choice over their behavior. Based on the cited research, it would seem logical to assume that if a person is provided with a higher degree of behavioral alternatives their level of satisfaction with their decision should also increase. Research conducted in organizations has lent support for this assumption.

A very salient issue within an organization is how to maximize the effects of employee training programs. The majority of training research conducted on such programs has taken an organizational perspective (Goldstein, 1974). Hicks and Klimoski (1987) approached employee training from the employees point of view. They took into consideration issues that were relevant to the employees, the employees expectations of the training program, attitudes toward the training program, and decisions to select training programs. Hicks and Klimoski 
manipulated the type of information provided to the employees regarding the training program (realistic preview / overly positive preview). The degree of choice to attend the training program was also manipulated (low choice / high choice). The low choice participants were required to attend the training program. The high choice participants were allowed to select from five different training sessions. Results indicate that the employees who received a realistic preview and had a high degree of choice were more satisfied with the training program. These employees were also more motivated to learn the material presented in the training program. The freedom of choice to attend the training program provided a stronger effect on the dependent variable than the type of preview information provided. Results suggest that one way an organization can increase the material learned in their training programs is to provide some degree of choice to the employees.

Simulation research which has focused on organizational applications provides support for the positive effect of having a choice on a person's level of satisfaction (Vanderslice, Rice, \& Julian, 1987). vanderslice et al. sought to determine the effect that participation in decision making has on worker's satisfaction and their productivity. Participation in decision making in this study was manipulated through the 
instruction given to the participant. Participants in tire high participation company had the freedom to choose what product they wanted to produce, what supplies to buy, and what position each nember of the group was to hold. Participants in the low participation company were provided with instructions about what they were to produce, what supplies they were to buy, and the positions each member was to occupy. The different companies were measured for their amount of production and their satisfaction with the production process. Results concluded that individuals in the high participation company reported that they were significantly more satisfied with the production process than the individuals in the low participation company. Participation in decision making can be equated with an increase in the number of choices a person is given to perform a task or to set up strategies to reach a goal. Early and Kanfer (1985) tested this assumption by assessing the effects of different levels of participation (choice) in goal setting on an individual's acceptance and satisfaction with the goal and strategy used to reach the goal. Participation in goal setting was divided into three levels: choice in setting the goal, as well as designing and implementing a strategy to achieve the goal (high choice); choice in setting the goal but 
assigned strategy for achieving the goal (moderate choice); and no choice with assigned goal or strategy to reach the goal (no choice). Results revealed that individuals in the high choice condition were significantly more satisfied with the goals set than were the individuals in the moderate and no choice conditions. In addition, individuals in the high and moderate choice conditions were significantly more accepting of the goals set than the individuals in the no choice conditions. These results support the assertion that participation in decision making can be equated with an increase in choice over subsequent behaviors in terms of a positive effect on satisfaction.

The literature cited above has provided support for the connection between number of decisional choices and subsequent level of satisfaction with decisional choice. However, some research in this area has not produced consistent findings. A study conducted by Reibstein, Youngblood, and Fromkin (1975) demonstrated that increasing the number of decisional choices does not always lead to an increase in satisfaction. Reibstein et al. studied the effect of increased number of choices and perceived decision freedom as a determinant of consumer satisfaction. Participants were told that they were part of a soft drink taste-test study. Participants were randomly assigned to one of two conditions (low choice) 
high choice). The low choice condition allowed the subjects to approach a soft-drink dispenser and select their favorite soft drink from two different flàvor choices. The high choice condition allowed the subjects to select their favorite soft-drink from four different flavor choices. Participants completed a questionnaire which was designed to measure their satisfaction with the chosen alternative. Results indicated a nonsignificant difference between the number of choices provided and a person's level of satisfaction with their decisional choice. The manipulation check indicated that there was a significant difference between the groups perceived decisional freedom.

Harrison, Lewis, and straka (1984) used a proof reading task to assess the relationship between decisional choice and level of satisfaction. Participants were either in a no choice condition (each individual was tola which method of proof reading to use: manual method) or a high choice condition (each individual selected their proof reading method from two alternatives: manual or computer assisted). Participants who selected the computer method were dropped from the study and told the purpose of the research. Four 9-point semantic differentials measuring task satisfaction were used. The four scales were averaged and found to form an internaliy 
consistent scale (coefficient alpha $=.90$ ). Results indicated a nonsignificant difference between degree of choice and a person's level of satisfaction with the task.

In addition, Harrison et al. examined the relationship between a person's locus of control, their freedom of choice, and subsequent level of satisfaction with their choice. An analysis of variance of these ratings revealed a significant interaction between degree of choice and a person's locus of control. Based on these results, one possible explanation for the research findings indicating that choice is not related to satisfaction is that the researchers may not have assessed participants' locus of control. Even those studies which have revealed a significant relationship between degree of choice and level of satisfaction may not have accounted for all the potential variance in the relationship when locus of control is not taken into account.

Locus of Control, Level of Satisfaction, and Level of Choice

Research has provided some support for the contention that having a choice over behavioral activities influences a person's level of satisfaction. It has also been shown that this relationship may not apply to all individuals equally. A personality variable 
that may act as a moderating variable on a person's level of satisfaction with their decisional choice is locus of control. In a review of the literature, Diener (1984) examined a wide variety of variables which were believed to influence a person's subjective-well-being (SWB). A personality trait that he noticed was consistently related to satisfaction is internality (having an internal locus of control). Locus of control (LOC) is generally concerned with a persons outlook on who or what controls their life events. The two orientations of LOC are internal and external. Individuals with an internal LOC perceive that they have control over the events in their life. Those with an external LOC perceive their life to be controlled by fate, chance, and powerful others. A variable which has been shown to be related to internality is the degree of perceived choice or control over one's life. It is reasonable to expect that a person who has a high degree of choice and has an internal LOC would be more satisfied with their life. In this same framework, it is expected that a person who has an external LOC should be more satisfied in an environment where there is little freedom of choice. Research which has investigated the effect a person's locus of control has on their level of satisfaction suggests that internals are more satisfied in situations with choice, 
whereas externals are less satisfied in situations with choice. Research at the organizational level has shown internals are more satisfied with participative decision making, whereas externals are more satisfied with assigned goals (Spector, 1982). In addition, spector suggests that internals perceive a greater number of alternatives than do externals in a choice situation. Commitment to Choice, Degree of Choice, \& Locus of Control

Research investigating the construct of commitment has operationalized the term in different manners. The present study will use the definition set forth by Porter, Steers, Mowday, and Boulian (1974). Porter et al. define organizational commitment as a strong belief in and acceptance of the organization's goals and values, a willingness to exert considerable effort on behalf of the organization, and a strong desire to remain in the organization. Several studies, presented below, have investigated the determinants and antecedents of organizational commitment.

In an extensive review of the literature on the demographic variables related to organizational commitment, Salancik (1977) concluded that a person with greater tenure in an organization is more committed. He also found that older workers tend to be more committed to the organization. Steers (1977), in a conceptual 
explanation of the relationship between demographic variables and commitment, suggests that commitment operates as a form of exchange. When a person perceives the exchange as appropriate, then commitment will grow.

Research which has investigated commitment beyond the demographic variables suggests that a person's personality and/or attribution process is an important component to commitment (Luthans, Baack, \& Taylor, 1987). specifically, a person's locus of control may be an important antecedent to commitment. Kiesler (1971) believes that the perceived level of choice a person has provides a strong effect on their commitment. He states that as choice increases, commitment increases. According to Salancik (1977), an important component of commitment is cognitive consistency. Cognitive consistency is a theoretical perspective which stipulates that a person will attempt to maintain a consistent relationship between their thoughts and actions. The most celebrated formulation of this position is Leon Festinger's (1957) theory of cognitive dissonance. As Festinger reasoned, when a person holds two cognitions (ideas about the state of events) that are consistent with each other, $\mathbf{s}$ (he) experiences a satisfying state of consonance. Festinger (1964) argued that people develop attitudes consistent with their choices. He recognized that decisions are 
committing and carry equivocal consequences for those who make them. When a person is committed and bound to a choice, s(he) will resolve their inconsistencies to produce attitudes consistent with the choice.

The existence and strength of a relationship between degree of choice and level of commitment are in accordance with an attributional analysis of commitment. Keisler (1971) asserts that increasing the number of choices for an act should increase commitment to that act. The relationship could be described as follows: an increase in choices increases the tendency to attribute causality for the act to self and hence also increase commitment. Hicks and Klimoski (1987) demonstrated this by showing that workers who were in a high choice condition were more committed to a training program and learned more than those individuals who were in a low choice condition.

Mayer, Duval, and Duval (1980) conducted a study to assess the effect perceived choice has on the amount of commitment to a decision. In addition, the relationship between perceived choice and self attribution was assessed. Participants were randomly assigned to one of four conditions. The researchers manipulated the degree of choice the subjects had in selecting one of two common strategies used in gin rummy. The high choice subjects indicated the strategy they were going to use in playing 
gin rummy. The no choice subjects were assigned the strategy to use in playing gin rummy. An analysis of the manipulation of perceived choice indicated that subjects in the high choice condition expressed greater perceived choice. Results revealed that the subjects in the high choice condition were less willing to change strategies than subjects in the no choice condition. Results indicated that commitment to the use of a strategy was higher when a choice was allowed.

Research Hypotheses,

The present study examined the relationship between degree of choice, locus of control, and subsequent level of satisfaction and commitment with a decision.

(1) It is hypothesized that there will be an interaction effect between locus of control and level of choice on an individual's level of satisfaction. It is predicted that a person with an internal locus of control will be more satisfied with an increase in choice. It is also predicted that a person with an external locus of control will be less satisfied with an increase in choice.

(2) It is hypothesized that there will be a significant main effect for level of choice on degree of commitment. It is predicted that those who choose from 
a greater number of alternatives will be more committed to their decision.

(3) It is hypothesized that there will be a positive relationship between level of satisfaction and level of commitment to a decisional choice.

Method

\section{Participants}

Participants were 288 (31\% males \& $69 \%$ females) upper level undergraduate students from two northeastern universities. The average age of the participants was 20 years. Each person's participation was on a voluntary basis and $s(h e)$ was treated in accord with the Ethical Principles of the American Psychological Association. Instruments

The degree of choice was experimentally manipulated by presenting the participants with one of three brief choice-scenarios that were developed for this study. Each of the three choice-scenarios depicts a brief biography of events which took place in a fictitious individual's life. The biography talks about the events that the individual encountered while selecting and applying to graduate school. The sex of the individual in the biography is not revealed to remain gender neutral. The manipulated variable in the choice-scenarios was the number of universities into which the individual was accepted. There were three levels: the individual was 
accepted into either one, three, or five universities. The length of the biographies is the same for each condition. These are given in Appendices $\mathrm{A}$ to $\mathrm{C}$.

Results from two independently conducted pilot studies revealed that the degree of choice for the three scenarios was perceived as different. Thus, it is believed that the use of one, three, and five universities in the choice-scenarios is sufficient to assess the effects of increased number of choices on a person's satisfaction and commitment with their decision.

This study employed four sets of measures and one manipulation check. The constructs which were being assessed by these measures were the participants' level of satisfaction, locus of control, level of commitment, and perceived choice. The first independent variable, degree of choice, was manipulated through the use of biographical scenarios described earlier. The second independent variable, locus of control, was assessed using Rotter's Internal - External Scale. The first dependent construct, satisfaction, was assessed by two satisfaction scales (Kunin's Faces Scale, Job in General scale). The second dependent construct, commitment, was assessed by the organizational Commitment Questionnaire (OCQ) . 
The Kunin (1955) Faces Scale is a one-item measure of global satisfaction. Participants were presented with a series of five circular faces, ranging from smiling to frowning and asked to indicate which face accurately expressed their level of satisfaction with their present situation (see Appendix D). The circular faces were selected over male faces to remain gender neutral. The present study employed the Faces scale as a measure of global satisfaction with one's situation. The instructions were altered to reflect a measure of the present situation of graduate school acceptance. The Faces scale has been shown to have good convergent validity and has been revealed as a good measure of global satisfaction (Brief \& Roberson, 1989).

The Job in General (JIG) scale (Ironson, Smith, Brannick, Gibson, \& Paul, 1989) is an 18-item measure of general job satisfaction. The present study employed a slight variant of the JIG to represent a measure of satisfaction with a person's decision for graduate school. The 18 adjectives/short phrases were not altered; the instructions were modified to reflect a graduate school perspective as compared to a job setting (see Appendix E). The JIG has been shown to have excellent internal consistency with coefficient alpha ranging from .91 - .95. It has also been shown to have acceptable convergent validity with other general scales of job 
satisfaction. Specifically the JIG and the FACES scale have been shown to have a correlation of $r=.75$. The Organizational commitment Questionnaire (OCQ: Porter \& Smith, 1970) is a nine-item measure, where organizational commitment is defined in terms of one's identification with the organization (see Appendix F). The OCQ was slightly altered to reflect a measure of commitment with a Graduate school program. The scale has very high internal consistency, measured by coefficient alpha, ranging from .82 to .93 . The scale has demonstrated relative stability over time (test-retest reliability, $r=.75$ over four months). In addition, the OCQ has been shown to have sound convergent validity, discriminant validity and predictive validity. A complete review of the psychometric properties of the $O C Q$ can be found in Mowday, steers, and Porter (1979).

$$
\text { Rotter's (1966) Internal-External (I-E) locus of }
$$
control scale was employed. The I-E scale consists of 23 locus of control items and six filler items (see Appendix G) . The response format of the scale is forced choice. Scores are calculated by suming the total number of externally oriented responses for each pair of choices. The range of scores is from $0-23$, with high scores representing externality and low scores internality. 


\section{Design}

This study used a 2 (locus of control) X 3 (level of choice) Multivariate Analysis of Variance (MANOVA) design. The two independent variables were the level of choice (low, medium, high) and the individual's locus of control (internal / external). The three dependent variables were the individual's score on the Job in General scale (JIG), Kunin's Faces (FACES) scale, and the Organizational Commitment Questionnaire (OCQ). Each participant completed Rotter's I-E scale to determine their locus of control (internal or external) and then was randomly assigned to one of the three level of choice conditions. Operational definitions of the three levels of choice are: the individual described in the biography scenario was accepted to one graduate school out of ten (low choice), the individual was accepted into three graduate schools out of ten (moderate choice), and the individual was accepted into five graduate schools out of ten (high choice).

\section{Procedure}

Participants were selected from upper level undergraduate courses (primarily juniors and seniors). The investigator recruited these individuals by providing a brief overview of the tasks they were asked to fulfill at the beginning of their class. All individuals who expressed a willingness to participate were given a list 
of dates and times that they could participate. An incentive to participate was provided by the researcher in the form of a $\$ 100.00$ lottery that was held at the conclusion of the data collection period. Each participant in the research was given an index card on which to write their name for the lottery drawing.

Upon arriving at the experimental setting the participants were first administered Rotter's InternalExternal locus of control scale. Upon completion of the scale the participants were randomly assigned to one of the three experimental conditions such that there was an equal number of internals and externals in each choice condition. Participant were then asked to read one of the three "choice scenarios."

After reading the scenarios, participants were asked to read the instruction for the JIG and complete the scale. The participants were then asked to read the instruction associated with the FACES scale and then complete the scale. Lastly, participants were asked to read the instructions associated with the $O C Q$ and then complete the scale.

\section{Results}

Data were analyzed for overall significance through a multivariate analysis of variance (MANOVA). The two independent variables analyzed were individuals' level of 
choice as described in the scenarios (low, medium, \& high) and the participants' locus of control score as measured by Rotter's I-E scale. Participants were categorized as having an internal locus of control if their score was 11 or lower. Participants were categorized as having an external locus of control if their score was 12 or greater. The cut off points were determined as appropriate based on a consultation with Professor Rotter regarding the dichotomization of his locus of control measure (J.B. Rotter, personal communication, February 12, 1991). There were 48 participants in each of the six cells, making a total of 288 participants. The three dependent variables under investigation were the participants' scores on the Job in General scale (JIG), Kunin's Faces Scale (FACES), and the organizational commitment Questionnaire (OCQ). In addition, exploratory post hoc data analyses were conducted to gain a complete understanding of the phenomena under investigation.

Results of the omnibus test for the first independent variable, level of choice, revealed a significant Wilk's Lambda of $.77 ; \underline{\mathrm{F}}(6,560)=12.84$, $\mathrm{p}<.001$. These results indicate that $23 \%$ of the variance in a linear combination of the dependent variables was due to the manipulation of level of choice an individual. was allowed. Results of the omnibus test for the second 
independent variable, locus of control, revealed a nonsignificant Wilk's Lambda of .99; $\underline{F}(3,280)=1.23$, $\underline{p}=0.295$. The results from the omnibus test for an interaction effect between level of choice and locus of control revealed a nonsignificant Wilk's Lambda of .97; $\underline{F}(6,560)=1.22, \underline{p}=0.296$.

Based on the overall significance revealed by the main effect for level of choice, these data were further analyzed using analysis of variance (ANOVA) and Tukey's Honestly Significant Difference (HSD) planned comparisons. In order to control for Type I error rate, significance levels were set at the .01 level for these follow-up ANOVAs and HSDs. The three dependent variables (JIG, FACES, OCQ) were analyzed separately with the independent variable level of choice. These analyses assess which dependent variables showed significant group differences on the independent variable.

Results from the first ANOVA indicated a significant effect for degree of satisfaction as measured by the JIG; $\underline{F}(2,282)=39.27, \underline{p}<.001$. Follow-up HSD tests revealed that individuals were significantly more satisfied with the chosen graduate school if it was selected from among five graduate programs compared to three or one graduate program. Results also revealed that individuals were significantly more satisfied with the 
graduate program if it was selected from among three graduate program choices than if the selection was from one graduate program. Table 1 presents the means and standard deviations for levels of satisfaction, as measured by the JIG, with the chosen graduate program

\section{Insert Table 1 about here}

based on the number of available choices. Figure 1 provides a graph of these same means, offering a clearer

\section{Insert Figure 1 about here}

illustration of the linear trend between choice and satisfaction.

Results from the second ANOVA indicated a significant effect for degree of satisfaction as measured by Kunin's Faces scale; $\mathrm{F}(2,282)=17.58, \mathrm{p}<.001$. Follow-up HSD tests revealed that individuals reported being significantly more satisfied with the chosen graduate program if it was selected from among five or three graduate program choices compared to one graduate program. Results revealed that individuals were not significantly more satisfied with a chosen graduate program if it was selected from five alternatives compared to three graduate program choices. Table 2 gives 
the means and standard deviations for level of satisfaction, as measured by the FACES scale, for each of Insert Table 2 about here

the three levels of choice. Figure 2 shows a linear trend of the mean FACES satisfaction scores with increasing levels of choice.

Insert Figure 2 about here

Results from the third ANOVA indicated a significant effect for degree of commitment as measured by the OCQ; $\underline{F}$ $(2,282)=11.62, \underline{p}<.001$. Follow-up HSD tests revealed that individuals indicated that they would be more committed to the chosen graduate program if it was selected from among five graduate programs compared to three or one graduate program. Results also revealed that individuals reported that they would not be more committed to a graduate program if they selected the graduate program from three graduate program choices than if the selection was from one graduate program. Table 3

Insert Table 3 about here 
provides the means and standard deviations for levels of comitment, as measured by the $O C Q$, with a graduate program based on the number of available choices. Figure 3 graphs the mean commitment scores across the three levels of choice, revealing a linear trend.

Insert Figure 3 about here

Based on the nonsignificant main effect for the second independent variable, locus of control, follow-up ANOVAs were not warranted. Table 4 provides the means and Insert Table 4 about here

standard deviations for locus of control for the three dependent variables (JIG, FACES, \& OCQ). Table 5 provides a frequency distribution of scores on Rotter's locus of control scale for the 288 participants in this study.

Insert Table 5 about here

\section{Manipulation Check}

The effectiveness of the choice manipulation was assessed by asking each participant to indicate how much perceived choice they had in attending a graduate program 
on a 5-point Likert scale (with 1 being a little choice and 5 being much choice). Data were analyzed by an ANOVA and Tukey's HSD. Results indicate significant group differences for level of choice, $\underline{F}(2,282)=17.40, \mathrm{p}$ $<.001$. HSD follow-up tests revealed that the participants' perceived choice was significantly different at each level of choice. These results lend support for the effectiveness of the level of choice manipulation.

Results also revealed significant group differences for locus of control, $\underline{F}(1,282)=4.26, \underline{p}<.05$. Internals perceived that they had more choice (mean = 3.56) than that perceived by externals (mean $=3.31$ ) . These results are in accord with previous research which has alluded to the belief that internals may perceive the presence of more choice compared to externals in the same situation.

\section{Intercorrelation Among Dependent Measures}

A Pearson Product Moment Correlation was conducted to assess the relationship between an individual's level of satisfaction with their choice and their degree of commitment to the decision. In accord with previously cited literature, the Job in General scale was significantly related to Kunin's Faces Scale $(r=.72$, $\mathrm{p}<.01$ ). The Organizational commitment Questionnaire was significantly related to both the Job in General Scale 
$(r=.46, p<.01)$ and Kunin's Faces scale $(r=.47$, $\mathrm{p}<.01)$.

Exploratory Data Analysis

In the spirit of post hoc data analysis, the data were further analyzed to determine if the second independent variable, locus of control, may be better understood by dichotomizing Rotter's scale using the upper and lower third of participants' scores. It is reasonable to expect that if locus of control had no effect on satisfaction and commitment then separating the participants into the upper and lower one third of scores would not change the results found using the mean split. Conversely, if locus of control has some effect on an individual's satisfaction and commitment then using the upper and lower one third of scores may provide a more realistic perspective between the way an internal and an external might react to an increase in choice.

Individuals who scored a 13 or greater on Rotter's I-E scale were categorized as the upper one third (Externals) and the lower one third were individuals who scored a 9 or lower (Internals). Data were analyzed using a MANOVA. Results of the omnibus test revealed a significant Wilk's Lambda of .95 for locus of control; $\underline{F}$ $(3,190)=3.20, p=.024$. These results indicate that $5 \%$ of the variance in a linear combination of the dependent 
variables was due to an individual's locus of control. A nonsignificant interaction between locus of control and level of choice was revealed with a Wilk's Lambda of .95; $\underline{E}(6,380)=1.47, \underline{p}=0.18$. Based on the results of the main effect for locus of control, follow-up ANOVAs were conducted for each dependent variable separately to assess which variable contributed to the overall significance. Because this analysis was of an exploratory nature, the alpha level was set at .05 for the separate ANOVAS.

Results for the first ANOVA, using the JIG scale, revealed a significant difference between internals level of satisfaction (mean $=69.61$ ) and externals level of satisfaction (mean $=65.28$ ) with their chosen graduate program $\underline{F}(1,192)=6.03, \underline{p}<.05$. Figure 4 provides a graphic comparison between the use of the mean split of

Insert Figure 4 about here

LOC (left graph) and the upper third and lower third split of IOC (right graph). These results indicate that LOC has an effect on a person's level of satisfaction with choice. As Figure 4 indicates, internals' level of satisfaction moves in a linear fashion at each level of choice. Externals' level of satisfaction increases rapidly from one choice to three choices and then almost 
levels off from three choices to five choices.

Results for the second ANOVA, using Kunin's Faces scale revealed a nonsignificant difference between internals level of satisfaction (mean $=4.10$ ) and externals level of satisfaction (mean $=3.88$ ) with their chosen graduate school program $\underline{\mathrm{F}}(1,192)=2.53, \mathrm{p}=$ 0.11 .

Lastly, results for the third ANOVA, using the OCQ, revealed a significant difference between internals degree of commitment (mean $=5.41$ ) and externals degree of commitment (mean $=5.05$ ) with their chosen graduate school $\mathrm{F}(1,192)=7.02, \underline{p}<.01$. In addition an interaction effect was revealed between locus of control and level of choice $\mathrm{F}(2,192)=3.61, \underline{\underline{p}}=.03$. Figure 5 provides a graphic comparison between the mean split on

Insert Figure 5 about here

LOC (left graph) and the upper third and lower third split on LOC (right graph). These results indicate that individuals with an internal LOC react differently than individuals with an external Loc to an increase in choice. Figure 5 clearly illustrates these results. Internals' degree of commitment is relatively unchanged when level of choice increases from one to three, whereas 
externals' degree of commitment increases dranatically. Conversely, internals' level of commitment dramatically changes when level of choice increases from three to five, whereas externals' degree of commitment levels off rapidly.

\section{Discussion}

The present study was designed to assess how level of decisional choice effects an individual's level of satisfaction and commitment with the chosen decision. It was hypothesized that an individual's attributional process (i.e. locus of control) would mediate this relationship between level of choice and degree of satisfaction. The first hypothesis stated that there would be an interaction between an individual's locus of control and their degree of decisional choice. It was predicted that a person with an internal locus of control would be more satisfied with an increase in choice. It was also predicted that a person with an external locus of control would be less satisfied with an increase in choice.

\section{Hypothesis one}

The results of the analysis failed to support hypothesis one. It was found that individuals with an internal locus of control were significantly more satisfied with an increase in choice as predicted. But, it was also revealed that individuals with an external 
locus of control were also significantly more satisfied with an increase in decisional choice.

The nonsignificant interaction between a person's locus of control and level of decisional choice can be explored within the context of the area of choice examined in the present study. The present study used brief scenarios that described an individual's attempt to get accepted into a graduate school program. The scenarios described the person getting accepted to either one, three, or five graduate school programs. For most individuals being accepted into a graduate program is a very satisfying achievement. The results of this study indicate that being accepted into a graduate program is a very salient issue within the lives of the individuals' who participated in the study. Regardless of an individual's locus of control, it appears that getting accepted into a higher number of graduate school programs is associated with an increase in satisfaction. This assertion is supported with the results attained for both measures of satisfaction (Job in General Scale \& Kunin's Faces Scale). A person's reported degree of satisfaction, as measured by the JIG scale, with the graduate program for which they would attend was significantly different at each level of the independent variable, degree of choice. A person's reported degree of satisfaction, as 
measured by Kunin's Faces scale, with the graduate program they would attend was significantly higher if the selection was from among five or three graduate school choices compared to if the selection was from one graduate school choice. A person's level of satisfaction was not significantly different if the selection increased from three to five graduate schools. Based on these findings a question arises as to whether a greater number of choices beyond five would increase an individuals level of satisfaction. Using the mean levels of satisfaction reported by the participants over the three levels of choice, a linear trend for both measures of satisfaction is apparent (see Figures $1 \& 2$ ). Intuitively it would be expected that at some point, the level of satisfaction expressed by an individual based on the number of choices available would reach a ceiling point. The point at which a ceiling effect might occur would be an interesting area to investigate for future research. The present study did not encounter a ceiling effect for satisfaction across the three levels of choice. It is interesting to speculate, however, that satisfaction would probably level off, and potentially start decreasing if too many more choices were provided. Hypothes is Two

The second hypothesis stated that there would be a significant main effect for level of choice on degree of 
commitment. It was predicted that those individuals who chose a graduate program from a greater number of alternatives would be more committed to their decision. Results lend support for this hypothesis. It was found that individuals who selected the graduate program from five alternatives were significantly more committed to the graduate program than those individuals who selected a graduate program from three or one graduate program alternatives. Results also revealed that individuals selecting a graduate program from three alternatives were not significantly more committed with their choice than if the selection was from one graduate program.

The results of the second hypothesis are in accord with Salancik's (1977) notion of cognitive consistency. This theoretical perspective stipulates that a person will attempt to maintain a consistent relationship between their thoughts and actions. Therefore, an individual who selects their graduate program from a high number of graduate programs would report that they are more committed to the graduate program. Under the same circumstance if the person indicated that they were not committed to the graduate program they chose, there would be some degree of cognitive inconsistency for the person. Hypothesis Three

The third hypothesis stated that there would be a 
positive relationship between an individual's level of satisfaction and their level of commitment to a decisional choice. Results lend support for hypothesis three. It was revealed that there was a significant correlation between an individual's level of satisfaction and level of commitment. These results were consistent for both measure of satisfaction (JIG \& FACES).

The results of the present study provide strong support for the belief that increasing an individual's decisional alternatives may increase the person's level of satisfaction and commitment with their choice. The Effect for LoC

It is less clear what role a person's locus of control played in this relationship. In a post hoc examination of the study, several social factors may have contributed to the initial nonsignificant results for locus of control including: the nation was at war, the economy was in a recession, local government was faced with a major banking crisis, and most of the individuals in the sample were at an age that could make them eligible to be sent to war. Each of these factors are under the control of powerful others. Therefore, at the present time, a person who attributes life events from an internal locus of control perspective may be feeling a little less control over their lives.

Because previous research has not specifically 
investigated the difference between internals and externals on satisfaction and commitment, an a priori power analysis to determine appropriate sample size was not calculated. However, it could be argued that the sample size itself was a contributing factor to the nonsignificant results. In a post hoc analysis of the available power within this study, it was revealed that the sample size used was sufficient to assess a significant group difference if a group difference of .4 or more actually existed. In order to calculate power a few variables are needed; they are: sample size, alpha level, and effect size. When researchers estimate the possible effect size, they can either use previous research or a pilot study. The pilot study for this project was conducted by the researcher to determine the utility of the biographical scenarios to detect a difference on the JIG, FACES, and OCQ. Rotter's I-E scale was not used in the pilot study. Hence, neither of these two options were available in the present study. Cohen (1977) asserts that there are three commonly used effect sizes which can be employed to estimate power. The effect sizes are .2 (low), .5 (medium), and .8 (high).

In calculating the potential power available, the author used estimates of effect size from .2 to .6 with increasing increments of .1. With a sample size of 288 
(144 internals \& 144 externals) and an alpha level of .05, the estimates of power were .39, .71, .92,.98, and .99 respectively. Based on these findings it is the researcher's belief that there was sufficient power to detect a moderately low to large effect size, but not as good to detrect a low effect size. The power to detect an effect size of .2 or .3 is relatively low and it is possible that locus of control may have an effect of this magnitude and more participants would be needed in order to significantly find such a small effect.

other factors (methodological) which may have contributed to the lack of significance for the second independent variable, locus of control, are explored below. Rotter's Locus of Control measure is a continuous scale with higher scores representing greater externality and lower score representing greater internality. Even though there was support for the dichotomization of the scale at the mean, this method of separating internals and externals may have been inappropriate to reveal a small effect between internals and externals. An alternative method which could have been initially used to dichotomize the sample was to examine only the upper third and lower third of all the scores. This might increase the likelihood of achieving mean differences between internals and externals. 


\section{Exploratory Analysis}

The above assertion was found to be accurate when data were further analyzed using the upper third and lower third of participants' scores on Rotter's I-E scale. In this exploratory, post hoc analysis, it was found that internals were significantly more satisfied (as measured by the JIG) and committed (as measured by the $\mathrm{OCQ}$ ) compared to externals. The emergence of group differences between internals and externals provides support for dichotomization of Rotter's I-E scale using the upper third and lower third of scores. Individuals who can not clearly be categorized as having an internal locus of control or an external locus of control are most likely the same individuals who will shift in their beliefs based on the situation/circumstances in their life at the present time. Individuals who score in the upper and lower third on Rotter's I-E scale are less likely to shift in their beliefs compared to the middle one third. The data in this study was collected during adverse social circumstances.

If locus of control had no effect on an individual's level of satisfaction with a decisional choice, then a comparison of graphs between the two distributions of scores (mean split or one third split) would be similar. This does not appear to be the case. Figure 4 (comparison 
of the JIG) provides support for the presence of a small effect for locus of control. Splitting the sample by the upper and lower one third acts as a noise reduction procedure. The effect LOC has on an individuals satisfaction with an increase in decisional choice is a very small effect. Therefore, using a more accurate measure of a person's attributional process teased out this small, but significant, effect for Loc. As stated earlier, getting into graduate school is a highly satisfying achievement for most individuals. The small effect found for locus of control under these circumstances is encouraging for research using a more moderate to low satisfying situation.

An interesting and unexpected finding was the effect LOC has on an individual's commitment to a decisional choice. Figure 5 illustrates these findings very clearly. Internals were found to be more committed to their decisional choice when the number of choices increased from three to five, whereas internals were found to have a reduction in commitment when the number of choices increased from one to three. Externals reaction to increases in decisional choice was inversely related to an internals reaction. Externals degree of commitment increased dramatically when the number of decisional choices increased from one to three, whereas the increase in commitment from three to five choices was moderate to 
low depending on the method of split used. Based on the effect found for LOC on an individual's commitment to an increase in choice, further research is recommended. Appropriateness of Sample

A criticism which is constantly being levied at researchers who use college students as their sample is how appropriate is the sample for the research question under study. The present study investigated the level of satisfaction and level of commitment an individual would experience based on the number of graduate schools into which they were accepted. For the purposes of this study, then, there was no more appropriate sample than college students. In addition, the results are in accord with previous research which has taken place outside the college setting and which has used participants who were not college students. Of course, another important question regarding the sample is, how generalizable are the results? Because this was not a random sample of college students, it is difficult to generalize beyond the universities examined in this study. Still, the consistency of findings across different studies with respect to more choice leading to more satisfaction and more commitment appears to be fairly robust and generalizable.

Mannell, Zuzanek, and Larson, (1988) found that 
older retired adults were significantly more satisfied with the activity they were engaged in if they had freely chosen the behavior. Similarly, Kimmel, Price, and walker (1978) found that individuals who voluntarily retired from work were significantly more satisfied with retirement than those individuals who were forced to retire. These findings support the link between increased choice and increased satisfaction, across several types of situations.

Research has also supported the assertion that an increase in choice would increase an individuals level of commitment. Our results found that students would be more committed to a graduate program if they selected it from a greater number of graduate programs. Hicks and Klimoski (1987) found that workers in an organization were significantly more committed to a training program if they were allowed to select the program from a number of available programs.

Additional Factors Effecting Satisfaction \& Commitment

It would be a gross oversight to assert that this phenomena would apply to all individuals in all situations. O'Reilly and Caldwell (1980) investigated additional factors which may influence an individual's satisfaction and commitment to a choice. O'Reilly and Caldwell assessed the impact of intrinsic and extrinsic factors related to job choice on subsequent satisfaction 
and commitment. Intrinsic factors were a person's interest in the job and chances for advancement in the company. Extrinsic factors were concern about family and geographic location. Results revealed that job choices made on intrinsic factors are related to an increase in both satisfaction and attitudinal commitment. External pressures such as family or finances were shown to be inversely related to attitudinal commitment, behavioral commitment, and job satisfaction. These results provide some insight into the mixed results found within previous research and offer some suggestions for future research.

Evidence attained by professional industrial consultants while working with displaced AT\&T employees found that older workers were not more satisfied with an increase in relocation options. It was found that these employees were more satisfied in a situation when they were told exactly what they were expected to do next. Although these findings are anecdotal, they lead to an interesting conclusion. A major factor which may influence the likelihood of an individual being more satisfied or committed with an increase in choice may be their previous experiences with having choices or not. This possible factor should be explored more in future studies. 


\section{Future Research Needs}

Future research is also needed to assess the point at which this apparent linear relationship between choice and satisfaction and choice and commitment becomes curvilinear. Perhaps up to five or six choices is seen as optimal, whereas having ten or more choices may seem less satisfying.

It is also believed that the use of a different set of circumstances, such as vacation spots or sport events which could be attended, may be better suited to assess the effect locus of control has on an individual's satisfaction with their choice. Getting accepted into graduate school may be too important of an event for a difference between internals and externals to be detected. Future research is also needed to determine under what circumstances a difference between internals and externals, with regard to satisfaction and commitment with levels of available choices, can be assessed. Implications and Applications

The primary implication which can be asserted based on the results of this study are that increasing an individual's level of behavioral choice can effect their level of satisfaction and commitment. If the results of the present study are accurate, a more important question is under what circumstances can these finding be applied? 
More precisely stated, what are the applications of these results?

Knowledge that an increase in choice can affect an individual's level of satisfaction and commitment to their behavioral choice can be utilized from an individual's perspective as well as from an industrial employer's or academic adviser's perspective.

The application from an individual's perspective follows a logical formula. If I understand that my level of satisfaction and commitment with a behavioral choice may increase when I select from a variety of alternatives, I should increase my behavioral alternatives whenever possible. clearly stated, I should put myself in situations with a greater number of behavioral choices. When applying for jobs I should send out a greater number of resumes. When selecting a movie to go see I should go to a large showcase cinema or a $\mathrm{video}$ store such as Blockbuster Video instead of the local convenient store. These examples are only a small sample of all the possible situations that an individual may have control over if they desire. Conversely, if I find that I do not like a lot of decisional choices, all I need to do is reduce my behavioral alternatives.

It is also reasonable to speculate that these results can be put to great use within the industrial 
sector. As the cited literature alluded to previously, an increase in behavioral choices directly affected an individual's satisfaction and commitment. Factors which have been found to be related to satisfaction and commitment in the work place are reduced absenteeism, reduced turnover, and increased tenure. Therefore, it would be beneficial to an organization to create more decisional freedom for their employees. Corporations could implement more participative decision making strategies. When a training program is required, a variety of times could be offered. The main point is to provide a variety of options so that employees perceive that they are allowed a choice over their behavior. This in return may reduce the costs associated with absenteeism and turnover.

A common complaint by students in the area of academia is that they are not allowed much choice in the courses that they need to take in a specific semester. This lack of choice could directly affect the students' satisfaction and commitment with the courses taken. In many fields of study, the curriculum is so tightly written that a student may be allowed only three or four electives. In comparison, other fields provide a much greater number of electives for their students. This phenomena is even apparent within subdivisions of the same discipline. In some graduate programs, there is a 
great difference between the freedom that an experimental psychology student has in designing their program of studies, for example, as compared to that of a clinical or industrial psychology student.

Based on the overall findings and implications of this study, further research is recommended to address the concerns outlined above. In order to be able to generalize future research findings, a greater number of situations should be investigated. 


\section{REFERENCES}

Austrom, D., \& Hanel, K. (1985). Psychological issues of single life in Canada: An exploratory study. Special Issue: Feminist psychology: Single life and married life and women's sexuality. International Journal of Women's Studies, $8(1)$, $12-23$.

Brief, A.P., \& Roberson, L. (1989). Job attitude organization: An exploratory study. Journal of Applied Social Psychology, 19(9), 717-727. Cohen, J. (1977). Statistical power analysis for the behavioral sciences, 2nd ed. New York: Academic Press.

Deiner, E. (1984). Subjective well-being. Psychological Bulletin, 95(3), 542-575. Earley, P.C., \& Kanfer, R. (1985). The influence of component participation and role models on goal acceptance, goal satisfaction, and performance. organizational Behavior and Human Decision Processes, $36(3), 378-390$. Festinger, L.A. (1957). A Theory of Cognitive Dissonance. Stanford, CA.: Stanford University Press. 
Festinger, L.A. (1964). Conflict, Decision, and Dissonance. Stanford, CA.: Stanford University Press.

Goldstein, I.L. (1974). Training: Program development and evaluation. Monterey, Calif.: Brooks cole.

Gorrell, J., \& Cramond, B. (1988). Students' attitude toward and use of written justification for multiple-choice answers. Educational and Psychological Measurement, $48(4), 935-943$. Harrison, W., Lewis, G., \& Straka, T. (1984). Locus of control, choice, and satisfaction with assigned task. Research in Personality, 18, $342-351$.

Hicks, W.D., \& Klimoski, R.J. (1987). Entry into training programs and its effect on training outcomes: A field experiment. Academy of Management Journal, 30 (3), 542-552. Ironson, G.H., Smith, P.C., Brannick, M.T., Gibson, W.M., \& Paul, K.B. (1989). Construction of a job in general scale: A comparison of global, composite, and specific measures. Journal of Applied Psychology, 74 (2), 193-200. Keisler. C.A. (1971). The psychology of commitment. New York: Academic Press. 
Kimmel, D.C., Price, F.K., \& Walker, J.W. (1978). Retirement choice and retirement satisfaction. Journal of Gerontology, 33(4), 575-585.

Kunin, T. (1955). The construction of a new type of attitude measure. Personnel Psychology, $\underline{8}$, $65-78$.

Larson, R. \& Csikszentmihalyi, M. (1983). The experience sampling method. In H.T. Reis (Eds.), New directions for naturalistic methods in the behavioral science. San Francisco: Josey-Bass. Luthans, F., Baack, D., \& Taylor, L. (1987). organizational commitment: Analysis of antecedents. Human Relations, 40(4), 219-236. Mannell, R.C., Zuzanek, J., \& Larson, R. (1988). Leisure states and "flow" experiences: Testing perceived freedom and intrinsic motivation hypotheses. Journal of Leisure Research, 20(4), $289-304$.

Mayer, F.S., Duval, S., \& Duval, V.H. (1980). An attributional analysis of commitment. Journal of Personality and Social Psychology, 39(6), $1072-1080$. Morris, J., \& Ingham, R. (1988). Choice of surgery for early breast cancer: Psychological considerations. Journal of Social Science Medicine, 27(11), 1257-1262. 
Mowday, R.T., Steers, R.M., \& Porter, L.W. (1979). The measurement of organizational commitment. Journal of Vocational Behavior, 14, 224-247. O'Reilly, C.A., \& Caldwell, D.F. (1980). Job choice: The impact of intrinsic and extrinsic factors on subsequent satisfaction and commitment. Journal of Applied Psychology, $\underline{65}(5), 559-565$.

Porter, L., \& Smith, F. (1970). The etiology of organizational comitment. Unpublished manuscript, University of California at Irvine. Porter, L.W., Steers, R.M., Mowday, R.T., \& Boulian (1974). Organizational commitment, job satisfaction, and turnover among psychiatric technicians. Journal of Applied Psychology, $\underline{59}(5), 603-609$.

Reibstein, D.J., Youngblood, S.A., \& Fromkin, H.L. (1975). Number of choices and perceived decision freedom as a determinant of satisfaction and consumer behavior. Journal of Applied Psychology， 60 (4), 434-437. Rotter, J. (1954). Social learning theory and clinical psychology. New York: Prentice-Hall. 
Rotter, J. (1966). Generalized expectancies for internal versus external control of reinforcement. Psychological Monographs, 80, Whole No. 609 ,

Salancik, G.R. (1977). Commitment and the control of organizational behavior. In B.M. Staw and G.R. Salancik (Eds.), New directions for organizational behavior (pp. 1-54). Chicago: st. Clair Press.

Spector, P.E. (1982). Behavior in organizations as a function of employee's locus of control. Psychological Bulletin, 91(3), 482-497. Steers, R.M. (1977). Antecedents and outcomes of organizational commitment. Administrative Science Quarterly, 17, 340-350.

Vanderslice, V.J., Rice, R.W. Julian, J.W. (1987). The effects of participation in decision-making on worker satisfaction and productivity: An organizational simulation. Journal of Applied Social Psychology, 17(2), 158-170. 
Appendix A

INSTRUCTIONS: The following description is a self-report of a series of events which have actually occurred over the last few months. The individual's identity and the identity of the universities are not disclosed to assure the person's anonymity. Please read the biography carefully. You will be asked to complete a series of questionnaires once you are finished.

\section{BIOGRAPHY}

I had known for a while that I would continue my education past the Bachelors degree. But it was only recently that $I$ aspired to attain a Doctorate degree. Knowing the effort required to get into graduate school I began reviewing several brochures of graduate programs to gain a better understanding of what to expect.

After a couple of months I narrowed my selection down to ten comparable universities. Each of them had their strengths and weaknesses but overall they were equally desirable. I acquired the application materials from each university and soon thereafter completed filling them out and mailed them back to their respective university. The only thing left for me to do was wait to hear from each university about their decision regarding my acceptance or rejection.

A few months passed and I slowly began hearing from each of the universities about whether I was accepted to their school. All ten schools replied within a couple weeks of each other. The results were that I had been accepted to one of the ten universities which I sought admission. In the weeks that followed, I thought about my present situation and my plans for attending graduate school in the fall. 


\section{Appendix B}

INSTRUCTIONS: The following description is a self-report of a series of events which have actually occurred over the last few months. The individual's identity and the identity of the universities are not disclosed to assure the person's anonymity. Please read the biography caref ully. You will be asked to complete a series of questionnaires once you are finished.

\section{BIOGRAPHY}

I had known for a while that I would continue my education past the Bachelors degree. But it was only recently that I aspired to attain a Doctorate degree. Knowing the effort required to get into graduate school I began reviewing several brochures of graduate programs to gain a better understanding of what to expect.

After a couple of months I narrowed my selection down to ten comparable universities. Each of them had their strengths and weaknesses but overall they were equally desirable. I acquired the application materials from each university and soon thereaf ter completed filling them out and mailed them back to their respective university. The only thing left for me to do was wait to hear from each university about their decision regarding my acceptance or rejection.

A few months passed and I slowly began hearing from each of the universities about whether I was accepted to their school. All ten schools replied within a couple weeks of each other. The results were that $I$ had been accepted to three of the ten universities which I sought admission. In the weeks that followed, I thought about my present situation and my plans for attending graduate school in the fall. 
Appendix C

INSTRUCTIONS: The following description is a self-report of a series of events which have actually occurred over the last few months. The individual's identity and the identity of the universities are not disclosed to assure the person's anonymity. Please read the biography carefully. You will be asked to complete a series of questionnaires once you are finished.

\section{BIOGRAPHY}

I had known for a while that I would continue my education past the Bachelors degree. But it was only recently that I aspired to attain a Doctorate degree. Knowing the effort required to get into graduate school I began reviewing several brochures of graduate programs to gain a better understanding of what to expect.

After a couple of months I narrowed my selection down to ten comparable universities. Each of them had their strengths and weaknesses but overall they were equally desirable. I acquired the application materiais from each university and soon thereafter completed filling them out and mailed them back to their respective university. The only thing left for me to do was wait to hear from each university about their decision regarding my acceptance or rejection.

A few months passed and I slowly began hearing from each of the universities about whether I was accepted to their school. All ten schools replied within a couple weeks of each other. The results were that $\mathrm{I}$ had been accepted to five of the ten universities which I sought admission. In the weeks that followed, I thought about my present situation and my plans for attending graduate school in the fall. 
Appendix D

\section{FACES SCALE}

\section{INBTROCTIONS :}

Presented below are five circular faces. Assuming the events in the biography you have just read occurred in your 1 ife, place an $\mathbf{x}$ underneath the face which best represents how satisfied you would be with the graduate school you would attend.
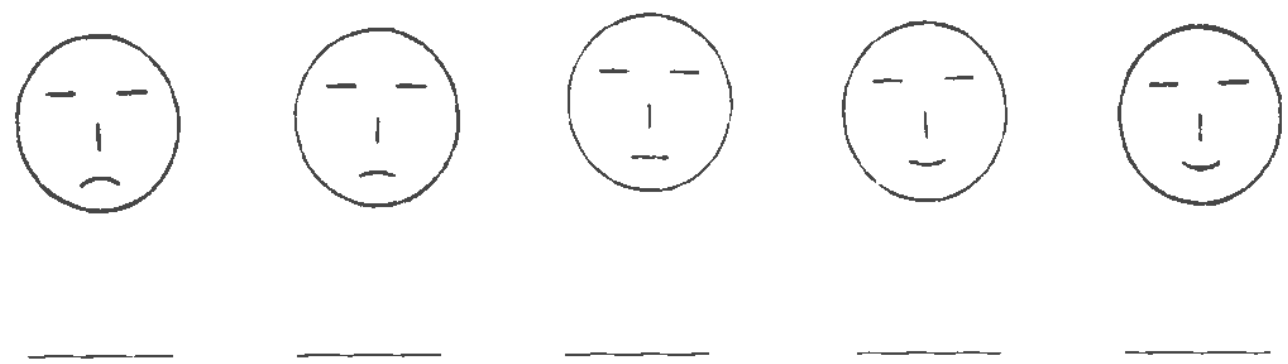
Appendix E

INSTRUCTIONS: Listed below are 18 adjectives / short phrases. Assuming the events in the biography occurred in your life, assess how accurate the adjectives / short phrases correspond to how you would perceive the present life situation. Based on the biographical information that you read, circle the appropriate point on the five-point scale to indicate how each of these adjectives / short phrases reflect your satisfaction with the graduate school you would attend.

1) PLEASANT

not accurate $\quad$ accurate very accurate

2) $\underline{\mathrm{BAD}}$

not accurate $\quad$ accurate $\quad$ very accurate

3) IDEAL

not accurate $\quad$ accurate $\quad$ very accurate

4) WASTE OF TIME

not accurate $\quad$ accurate $\quad$ very accurate

5) GOOD

$1---------2---------3--------4--------5$

not accurate accurate very accurate

6) UNDESIRABLE

not accurate $\quad$ accurate $\quad$ very accurate

7) WORTHWHILE

not accurate
accurate
(appendix continues) 


\section{Appendix E (continued)}

INSTRUCTIONS: Listed below are 18 adjectives / short phrases. Assuming the events in the biography occurred in your life, assess how accurate the adjectives / short phrases correspond to how you would perceive the present life situation. Based on the biographical information that you read, circle the appropriate point on the five-point scale to indicate how each of these adjectives / short phrases reflect your satisfaction with the graduate school you would attend.

\section{8) WORSE THAN MOST}

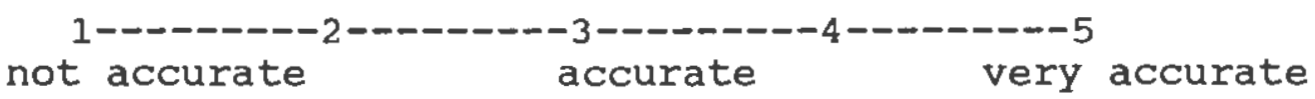

\section{9) ACCEPTABLE}

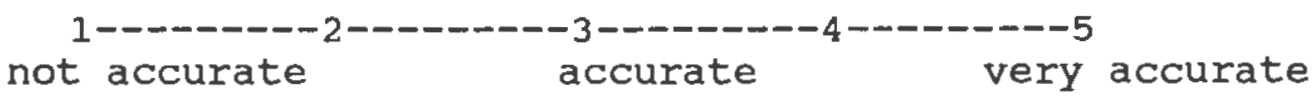

\section{0) SUPERIOR}

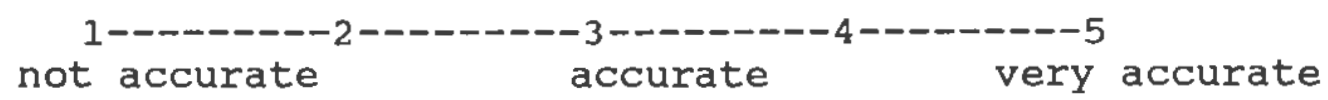

\section{1) BETTER THAN MOST}

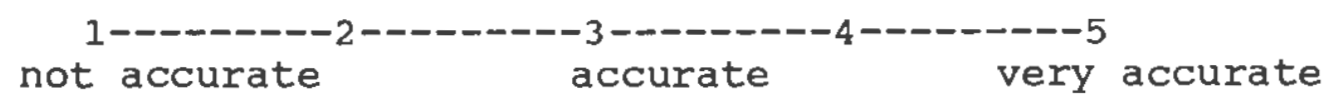

\section{2) DISAGREEABLE}

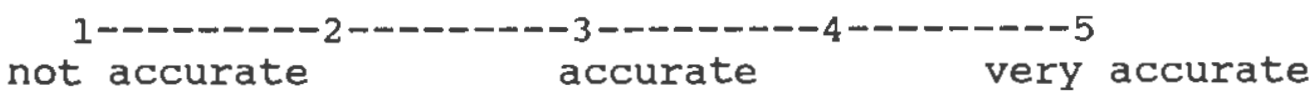

\section{3) MAKES ME CONTENT}

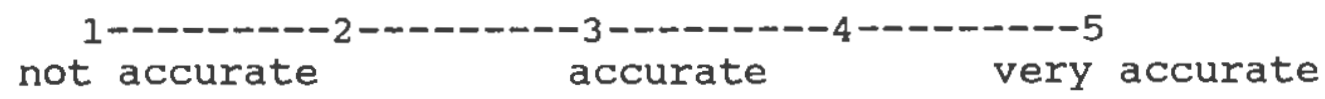

\section{4) INADEQUATE}

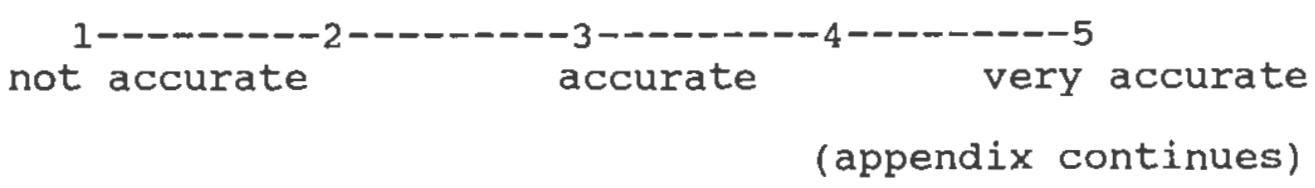


Appendix E (continued)

INSTRUCTIONS: Listed below are 18 adjectives / short phrases. Assuming the events in the biography occurred in your life, assess how accurate the adjectives / short phrases correspond to how you would perceive the present life situation. Based on the biographical information that you read, circle the appropriate point on the five-point scale to indicate how each of these adjectives / short phrases reflect your satisfaction with the graduate school you would attend.

\section{5) EXCELLENT}

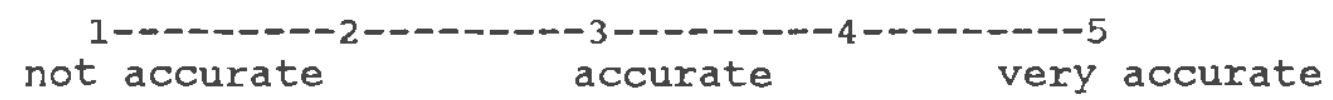

16) ROTTEN

not accurate $\quad$ accurate $\quad$ very accurate

17) ENJOYABLE

not accurate $\quad$ accurate $\quad$ very accurate

18) $\underline{\text { POOR }}$

not accurate $\quad$ accurate $\quad$ very accurate 
Appendix $\mathrm{F}$

INSTRUCTIONS

Listed below are a series of statements that represent possible feelings individuals' might have about their graduate program. With respect to your own feelings about the particular graduate program for which you would be enrolled, if you were the individual in the biography you just read, please indicate your degree of agreement or disagreement with each statement by circling one of the seven alternatives based on the choices listed below.

(1) Strongly Disagree

(2) Moderately Disagree

(3) Slightly Disagree

(4) Neither Disagree nor Agree

(5) Slightly Agree

(6) Moderately Agree

(7) Strongly Agree

1. I would be willing to put in a great deal of effort beyond that normally expected in order to help this graduate program be successful.

$$
1---\cdots-2-----3-\cdots--4-----5-----6----7
$$

2. I would talk up this graduate program to my friends as a great program to be enrolled in.

$$
1-----2-----3-----4------5-----6-----7
$$

3. I would accept almost any type of assignment in order to stay in this graduate program.

$$
1------2------3------4------5------6-----7
$$

4. I find that my values and the graduate program's values are very similar.

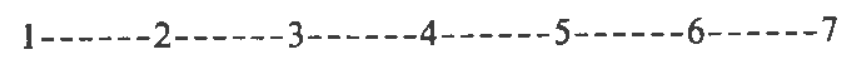

5. I would be proud to tell others that I am part of this graduate program.

$$
1-----2-----3-1---4-1---5-\cdots---6----7
$$




\section{Appendix F (continued)}

6. This graduate program would really inspire me to do my overall very best.

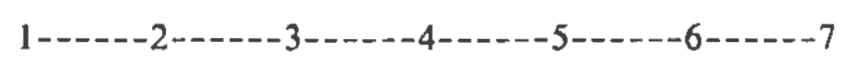

7. I am extremely glad that I was accepted into this graduate program over the other programs I was considering at the same time.

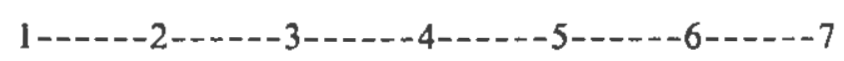

8. I would really care about the fate of this graduate program.

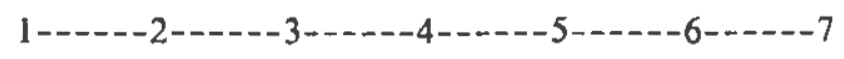

9. For me this would be the best of all possible graduate programs for which to be enrolled.

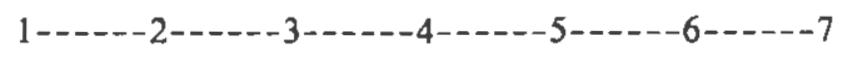




\section{Appendix $G$}

\section{INSTRUCTIONS}

This is a questionnaire to find out the way in which certain important events in our society affect different people. Each item consists of a pair of alternatives lettered $\underline{\mathrm{A}}$ or $\underline{\mathrm{B}}$. Please select the one statement of each pair (and only one) which you believe most closely applies to you. Be sure to select the one you actually believe to be more true rather than the one you think you should choose or the one you would like to be true. This is a measure of personal belief: obviously there are no right or wrong answers.

Your answers to the items on this inventory are to be recorded on a separate answer sheet which has been provided by the investigator. PLEASE REMOVE THIS ANSWER SHEET NOW. Print your name and any other information requested by the investigator on the answer sheet, then finish reading these directions. Do not start the questionnaire until you are told to do so.

Please answer these items carefully but do not spend too much time on any one item. Be sure to find an answer for every choice. Find the number of the item on the answer sheet and black-in the space under the letter $\underline{A}$ or B which you choose as the statement more true.

In some instances you may discover that you believe both statements or neither one. In such cases, be sure to select the one you more strongly believe to be the case, as far as you're concerned. Also try to respond to each item independently when making your choice; do not be influenced by your previous choice. 
Appendix G (continued)

\section{QUESTIONNAIRE ITEMS}

1. A. Children get into trouble because their parents punish them too much.

B. The trouble with most children nowadays is that their parents are too easy with them.

2. A. Many of the unhappy things in people's lives are partly due to bad luck.

B. People's misfortunes result from the mistakes they make.

3. A. One of the major reasons why we have wars is because people don't take enough interest in politics.

B. There will always be wars, no matter how hard people try to prevent them.

4. A. In the long run people get the respect they deserve in this world.

B. Unfortunately, an individual's worth often passes unrecognized no matter how hard $s($ he)

tries.

5. A. The idea that teachers are unfair to students is nonsense.

B. Most students don't realize the extent to which their grades are influenced by accidental happenings.

6. A. Without the right breaks one cannot be an effective leader.

B. Capable people who fail to become leaders have not taken advantage of their opportunities.

7. A. No matter how hard you try some people just don't like you.

B. People who can't get others to like them don't understand how to get along with others.

8. A. Heredity plays the major role in determining one's personality.

B. It is one's experiences in life which determine what they're like. 


\section{Appendix G (continued)}

QUESTIONNAIRE ITEMS

9. A. I have often found that what is going to happen will happen.

B. Trusting to fate has never turned out as well for me as making a decision to take a definite course of action.

10. A. In the case of the well prepared student there is rarely if ever such a thing as an unfair test.

B. Many times exam questions tend to be so unrelated to course work that studying is really useless.

11. A. Becoming a success is a matter of hard work, luck has little or nothing to do with it.

B. Getting a good job depends mainly on being in the right place at the right time.

12. A. The average citizen can have an influence in government decisions.

B. This world is run by the few people in power, and there is not much the little guy can do about it.

13. A. When I make plans, I am almost certain that I can make them work.

B. It is not always wise to plan too far ahead because many things turn out to be a matter of good or fortune anyhow.

14. A. There are certain people who are just no good.

B. There is some good in everybody.

15. A. In my case getting what I want has little or nothing to do with luck.

B. Many times we might just as well decide what to do by flipping a coin.

16. A. Who gets to be the boss often depends on who was lucky enough to be in the right place first.

B. Getting people to do the right thing depends upon ability, luck has little or nothing to do with it. 


\section{Appendix G (continued)}

\section{QUESTIONNAIRE ITEMS}

17. A. As far as world affairs are concerned, most of us are the victims of forces we can neither understand, nor control.

B. By taking an active part in political and social affairs the people can control world events.

18. A. Most people don't realize the extent to which their lives are controlled by accidental happenings.

B. There really is no such thing as "luck".

19. A. One should always be willing to admit mistakes.

B. It is usually best to cover up one's mistakes.

20. A. It is hard to know whether or not a person really likes you.

B. How many friends you have depends upon how nice a person you are.

21. A. In the long run the bad things that happen to us are balanced by the good ones.

B. Most misfortunes are the result of lack of ability, ignorance, laziness, or all three.

22. A. With enough effort we can wipe out political corruption.

B. It is difficult for people to have much control over the things politicians do in office.

23. A. Sometimes I can't understand how teachers arrive at the grades I get.

B. There is a direct connection between how hard I study and the grades I get.

24. A. A good leader expects people to decide for themselves what they should do.

B. A good leader makes it clear to everybody what their jobs are. 


\section{Appendix G (continued) \\ QUESTIONNAIRE ITEMS}

25. A. Many times I feel that I have little influence over the things that happen to me.

B. It is impossible for me to believe that chance or luck plays an important role in my life.

26. A. People are lonely because they don't try to be friendly.

B. There's not much use in trying too hard to please people, if they like you, they like you.

27. A. There is too much emphasis on athletics in high school.

B. Team sports are an excellent way to build character.

28. A. What happens to me is my own doing.

B. Sometimes I feel that I don't have enough control over the direction my life is taking.

29. A. Most of the time I can't understand why politicians behave the way they do.

B. In the long run the people are responsible for bad government on a national as well as a local level. 
Table 1

Means and Standard Deviations for Reported Satisfaction with Chosen Graduate Program as Measured with the JIG.

\begin{tabular}{ccc} 
Number of Graduate & \multicolumn{2}{c}{ Satisfaction } \\
School Choices & $\underline{\text { Means }}$ & $\underline{\text { Std Dev }}$ \\
1 & 59.36 & 13.62 \\
3 & 68.50 & 11.35 \\
5 & 73.41 & 7.94
\end{tabular}


Table 2

Means and standard Deviations for Reported Satisfaction with Chosen Graduate Program as Measured by the FACES

Number of Graduate

School Choices

1

3

5
Satisfaction

Means

Std Dev

3.57

1.00

4.02

0.87

4.28

0.61 
Table 3

Means and Standard Deviations for Reported Degree of Commitment with chosen Graduate Program.

Number of Graduate

School Choices

1

3

5

\section{Commitment}

Means

Std Dev

4.96

1.02

5.22

0.95

5.58

0.69 
Table 4

Mean Locus of control scores for Internals and Externals Across the Three Dependent Variables (JIG, FACES, \& OCO)

Dependent Variable

Job in General

Kunin's Faces

Organizational Commitment

Questionnaire
Locus of Control

Internals Externals

$\begin{array}{ll}68.31 & 65.86 \\ 4.02 & 3.88 \\ 5.32 & 5.19\end{array}$

68.31

65.86

. 88 
Table 5

Frequency Distribution of Scores on Rotter's I-E Scale

LOC Frequency Percent Cum. Freq. Cum. Percent

\begin{tabular}{|c|c|c|c|c|}
\hline 1 & 1 & 0.3 & 1 & 0.3 \\
\hline 2 & 1 & 0.3 & 2 & 0.7 \\
\hline 3 & 5 & 1.7 & 7 & 2.4 \\
\hline 4 & 2 & 0.7 & 9 & 3.1 \\
\hline 5 & 10 & 3.5 & 19 & 6.6 \\
\hline 6 & 12 & 4.2 & 31 & 10.8 \\
\hline 7 & 20 & 6.9 & 51 & 17.7 \\
\hline 8 & 17 & 5.9 & 68 & 23.6 \\
\hline 9 & 22 & 7.6 & 90 & 31.2 \\
\hline 10 & 28 & 9.7 & 118 & 41.0 \\
\hline 11 & 26 & 9.0 & 144 & 50.0 \\
\hline 12 & 36 & 12.5 & 180 & 62.5 \\
\hline 13 & 24 & 8.3 & 204 & 70.8 \\
\hline 14 & 18 & 6.3 & 222 & 77.1 \\
\hline 15 & 22 & 7.6 & 244 & 84.7 \\
\hline 16 & 18 & 6.3 & 262 & 91.0 \\
\hline 17 & 14 & 4.9 & 276 & 95.8 \\
\hline 18 & 6 & 2.1 & 282 & 97.9 \\
\hline 19 & 5 & 1.7 & 287 & 99.7 \\
\hline 21 & 1 & 0.3 & 288 & 100.0 \\
\hline
\end{tabular}


Figure 1. Illustration of the linear trend for satisfaction as measured by the JIG scale with increased choice

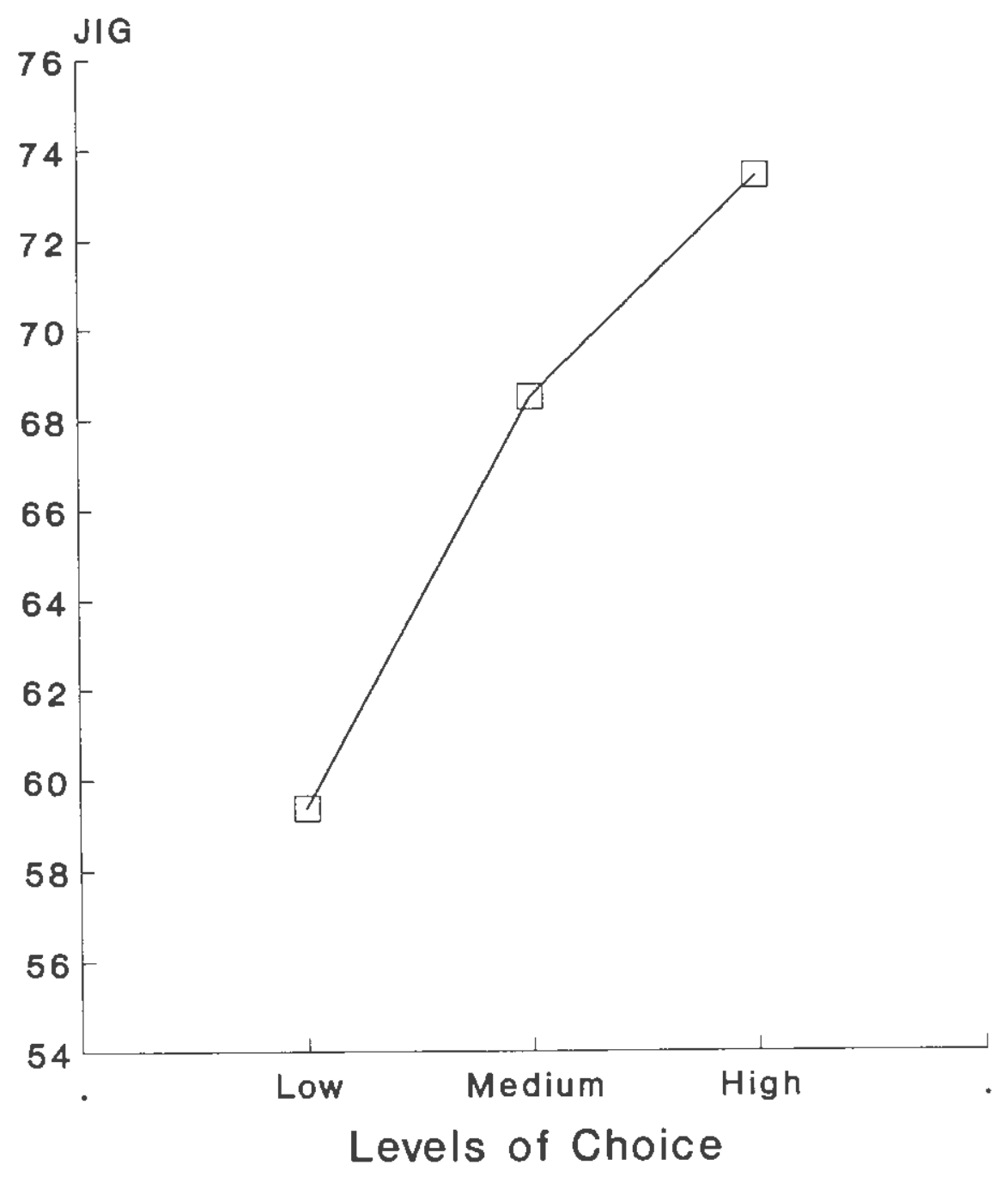


74

Figure 2. Illustration of the linear trend for satisfaction as measured by Kunin's Faces scale with increased choice

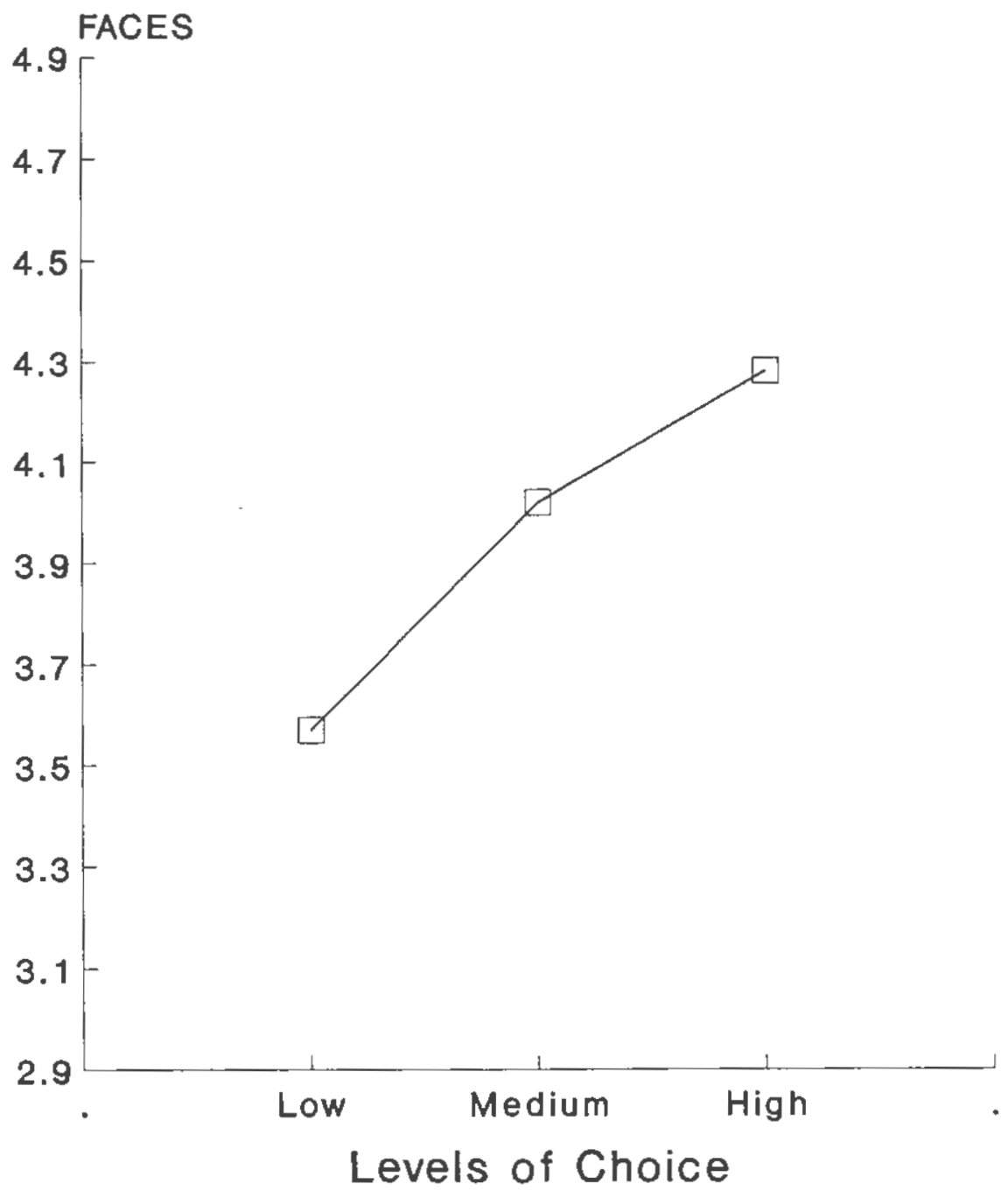


Figure 3. Illustration of the linear trend for commitment as measured by the OCQ with increased choice

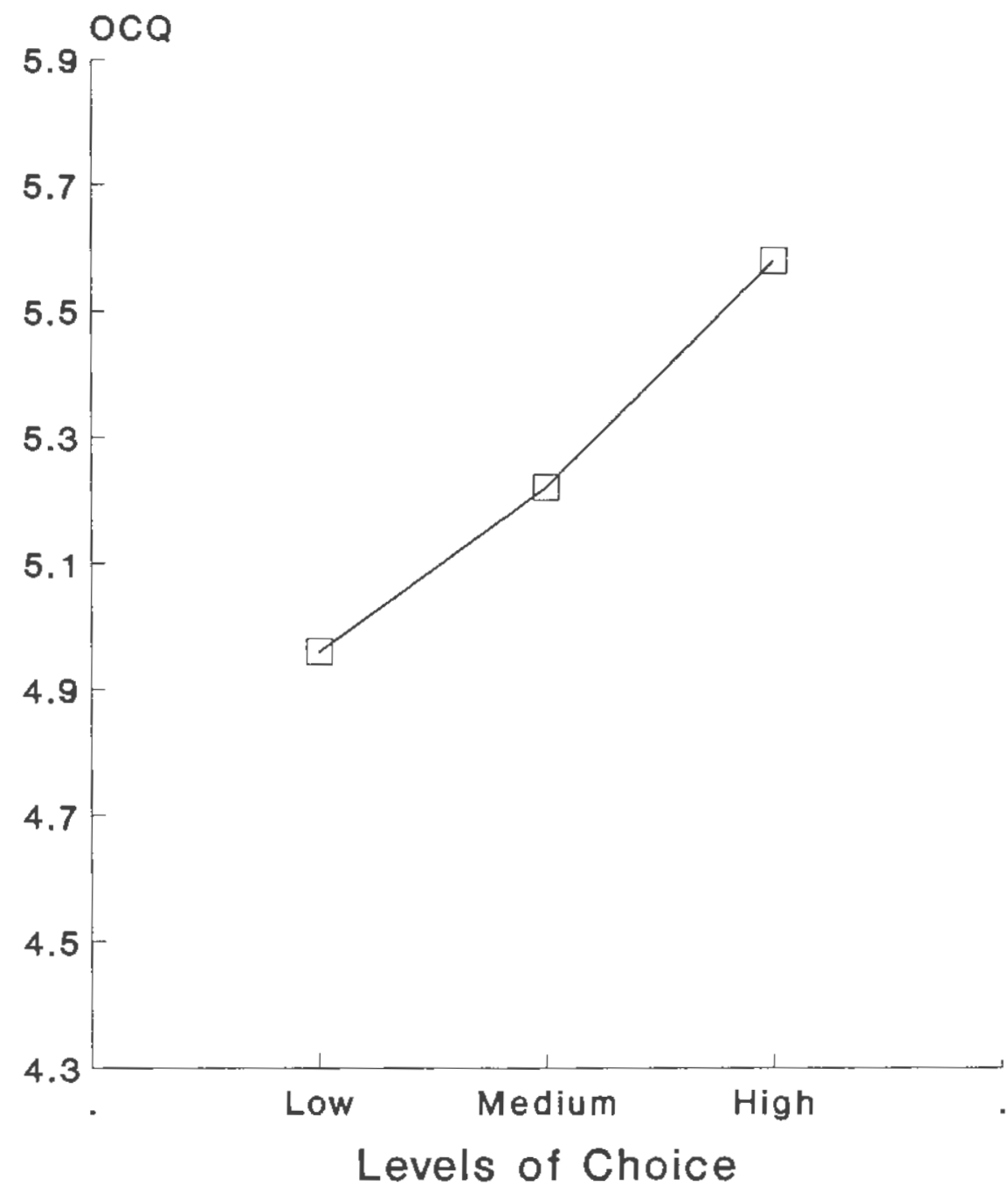




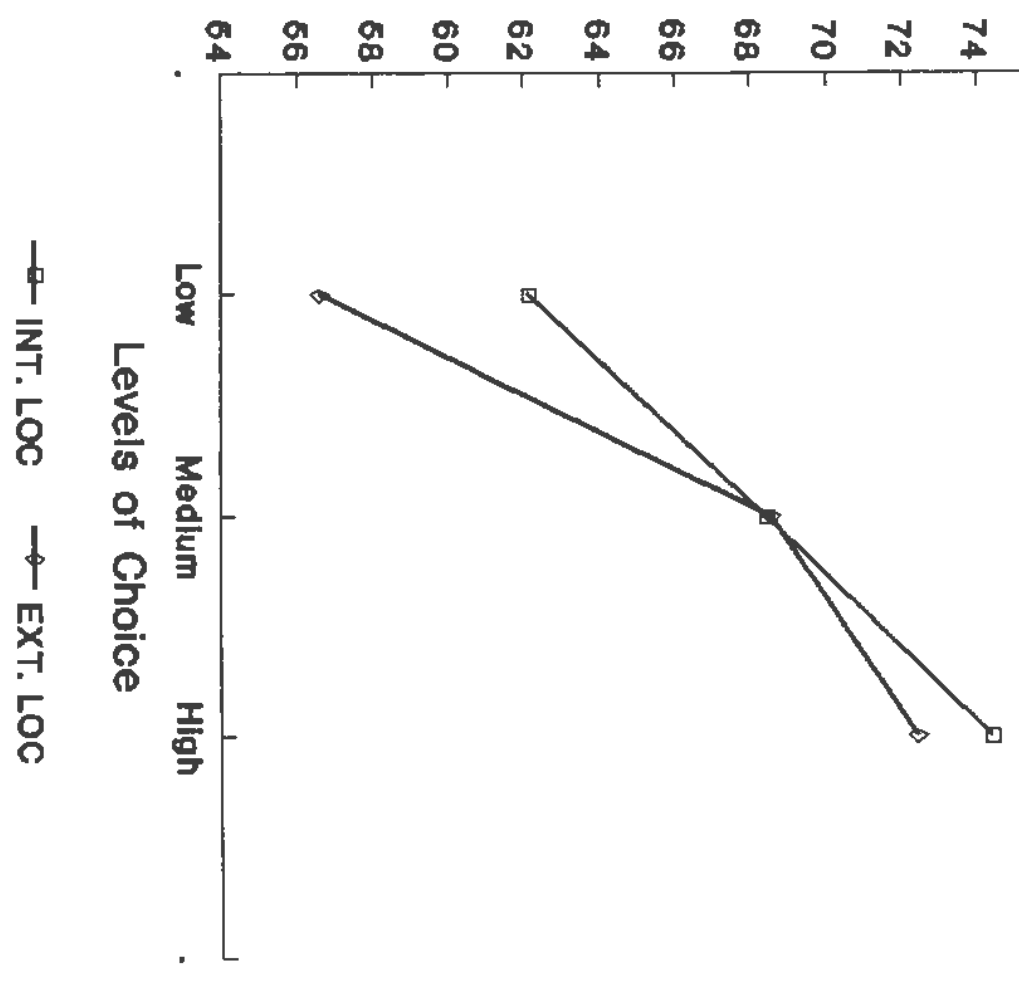

욤 든

点 

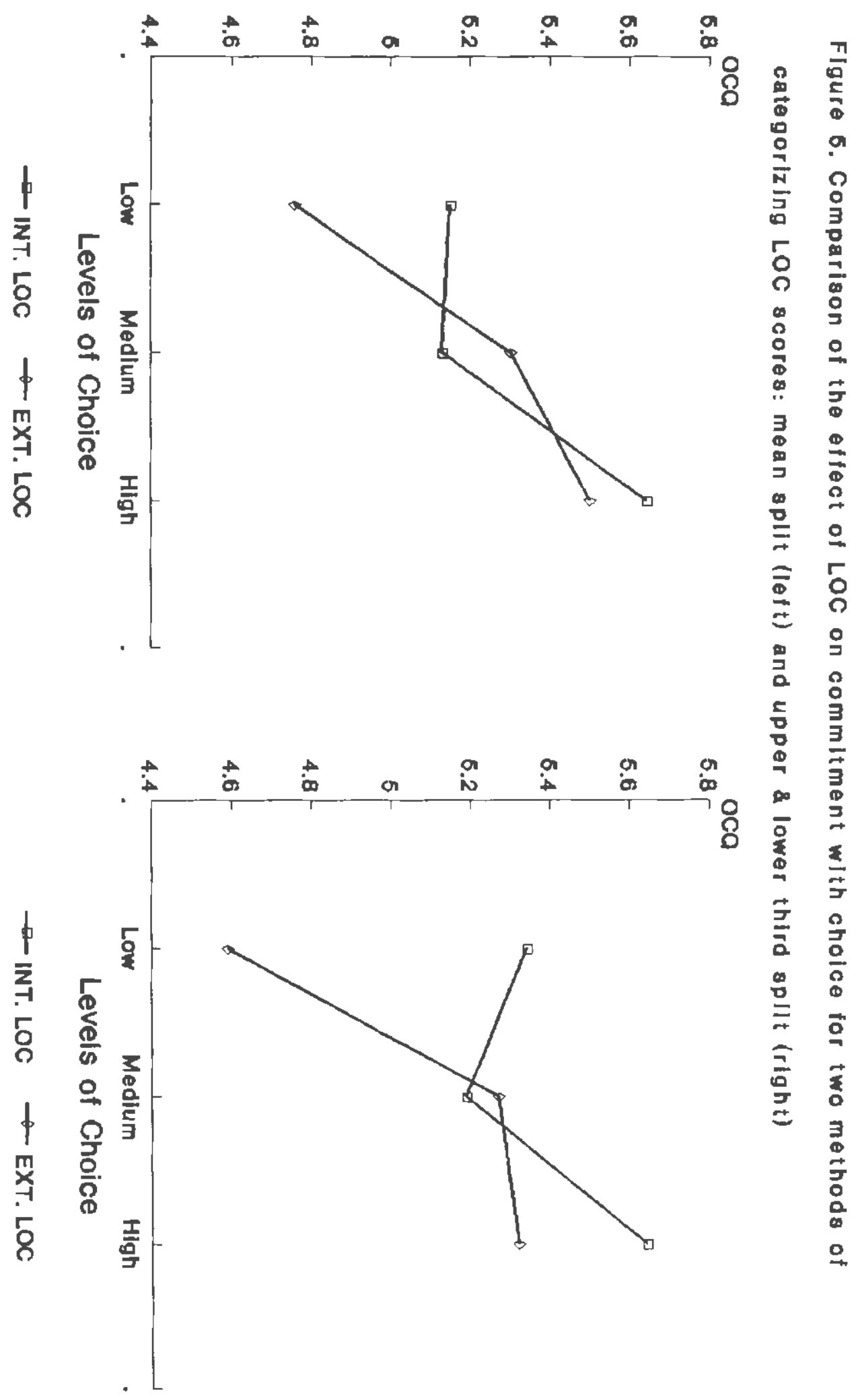
Bibliography

Austrom, D., \& Hanel, K. (1985). Psychological issues of single life in Canada: An exploratory study. Special Issue: Feminist psychology: Single life and married life and women's sexuality. International Journal of Women's Studies, 8 (1), 12-23.

Brief, A.P., \& Roberson, L. (1989). Job attitude organization: An exploratory study. Journal of Applied Social Psychology, 19(9), 717-727. Cohen, J. (1977). statistical power analysis for the behavioral sciences, 2nd ed. New York: Academic Press.

Deiner, E. (1984). Subjective well-being. Psychological Bulletin, 95(3), 542-575. Earley, P.C., \& Kanfer, R. (1985). The influence of component participation and role models on goal acceptance, goal satisfaction, and performance. Organizational Behavior and Human Decision Processes, $36(3), 378-390$. Festinger, L.A. (1957). A Theory of Cognitive Dissonance. Stanford, CA.: Stanford University Press. 
Festinger, L.A. (1964). Conflict, Decision, and

Dissonance. Stanford, CA.: Stanford University Press.

Goldstein, I.L. (1974). Training: Program

development and evaluation. Monterey, Calif.: Brooks Cole.

Gorrell, J., \& Cramond, B. (1988). Students'

attitude toward and use of written justification for multiple-choice answers. Educational and

Psychological Measurement, 48(4), 935-943. Harrison, W., Lewis, G., \& Straka, T. (1984). Locus of control, choice, and satisfaction with assigned task. Research in Personality, 18, $342-351$.

Hicks, W.D., \& Klimoski, R.J. (1987). Entry into training programs and its effect on training outcomes: A field experiment. Academy of Management Journal, 30(3), 542-552. Ironson, G.H., Smith, P.C., Brannick, M.T., Gibson, W.M., \& Paul, K.B. (1989). Construction of a job in general scale: A comparison of global, composite, and specific measures. Journal of Applied Psychology, 74(2), 193-200. Keisler, C.A. (1971). The psychology of commitment. New York: Academic Press. 
Kimmel, D.C., Price, F.K., \& Walker, J.W. (1978). Retirement choice and retirement satisfaction. Journal of Gerontology, 33(4), 575-585.

Kunin, T. (1955). The construction of a new type of attitude measure. Personnel Psychology, $\underline{8}$, $65-78$.

Larson, R. \& Csikszentmihalyi, M. (1983). The experience sampling method. In H.T. Reis (Eds.), New directions for naturalistic methods in the behavioral science. San Francisco: Josey-Bass. Luthans, F., Baack, D., \& Taylor, L. (1987). Organizational commitment: Analysis of antecedents. Human Relations, 40(4), 219-236. Mannell, R.C., Zuzanek, J., \& Larson, R. (1988). Leisure states and "flow" experiences: Testing perceived freedom and intrinsic motivation hypotheses. Journal of Leisure Research, $20(4)$, $289-304$.

Mayer, F.S., Duval, S., \& Duval, V.H. (1980). An attributional analysis of commitment. Journal of Personality and social Psychology, 39(6), $1072-1080$. Morris, J., \& Ingham, R. (1988). Choice of surgery for early breast cancer: Psychological considerations. Journal of Social science Medicine, 27(11), 1257-1262. 
Mowday, R.T., Steers, R.M., \& Porter, L.W. (1979). The measurement of organizational comnitment. Journal of Vocational Behavior, 14, 224-247. O'Reilly, C.A., \& Caldwell, D.F. (1980). Job choice: The impact of intrinsic and extrinsic factors on subsequent satisfaction and commitment. Journal of Applied Psychology, $\underline{6} \underline{(5)}, 559-565$.

Porter, L., \& Smith, F. (1970). The etiology of organizational comitment. Unpublished manuscript, University of California at Irvine. Porter, L.W., Steers, R.M., Mowday, R.T., \& Boulian (1974). Organizational commitment, job satisfaction, and turnover among psychiatric technicians. Journal of Applied Psychology, 59(5), 603-609.

Reibstein, D.J., Youngblood, S.A., \& Fromkin, H.L. (1975). Number of choices and perceived decision freedom as a determinant of satisfaction and consumer behavior. Journal of Applied Psychology, 60(4), 434-437. Rotter, J. (1954). Social learning theory and clinical psychology. New York: Prentice-Hall. 
Rotter, J. (1966). Generalized expectancies for internal versus external control of reinforcement. Psychological Monographs, 80 , Whole No. 609 .

Salancik, G.R. (1977). Commitment and the control of organizational behavior. In B.M. Staw and G.R. Salancik (Eds.), New directions for organizational behavior (pp. 1-54). Chicago: St. Clair Press.

Spector, P.E. (1982). Behavior in organizations as a function of employee's locus of control. Psychological Bulletin, 91(3), 482-497. Steers, R.M. (1977). Antecedents and outcomes of organizational commitment. Administrative Science Quarterly, 17, 340-350. Vanderslice, V.J., Rice, R.W. \& Julian, J.W. (1987). The effects of participation in decision-making on worker satisfaction and productivity: An organizational simulation. Journal of Applied Social Psychology, 17(2), 158-170. 